\title{
History of and differences between the Consumer Prices Index and Retail Prices Index
}

\section{Introduction}

During 2010, an assessment team from the UK Statistics Authority conducted a review of the Office for National Statistics' Consumer Price Indices. Their remit was to assess the indices against the Code of Practice for Official Statistics ${ }^{1}$. In December 2010, the team published their conclusions as Assessment Report $79^{2}$.

The Statistics Authority judged that the statistics covered by the report are readily accessible, produced according to sound methods and managed impartially and objectively in the public interest. They confirmed that the statistics are designated as National Statistics subject to the Office for National Statistics (ONS) implementing five enhancements or requirements. The third of these required the ONS to:

Publish information about the history and the reasons for the differences in scope and methods between the Consumer Prices Index (CPI) and Retail Prices Index (RPI); and explain the implications that these differences have for the uses to which these statistics are put.

This article attempts to meet that requirement but concentrates more on the history and differences. Further information on the strengths and weaknesses of the CPI and RPI in relation to their main uses will be published in a further article on 16 August 2011.

\section{History}

\section{Early History}

An interim Retail Prices Index was introduced in 1947 and this was made official in 1956 but before that, the first official index of consumer prices was introduced in 1914. Even before that, measurements of consumer price inflation existed and an article ${ }^{3}$ by Jim O'Donoghue, Louise Golding and Grahame Allen published in March 2004 described the creation of a composite price index covering the period from 1750 to 2003.

This index was created by linking together indices from several different published sources:

- 1750-1850: a price index compiled by Phelps-Brown and Hopkins based on records from local markets, the accounts of colleges and hospitals, records from the Navy Victualling 
service, and wholesale prices from the organised produce markets such as Smithfields wholesale meat market.

- 1850-1870: a retail price index produced by G H Wood partly from statistics in the Board of Trade's Report on Wholesale and Retail Prices and partly from data from Co-operative Society records.

- 1870-1947: an index constructed from components of the implied deflator for consumers' expenditure derived from estimates of consumers' expenditure valued at current and constant prices, and taken from the unofficial UK national accounts prepared by the Department of Applied Economics at Cambridge University.

- 1947-2003: the RPI.

In 1914, the Government first began a systematic, continuous check on the increase in the cost of living. The published figures initially covered only food but the index was expanded in 1916 to cover clothing, fuel and some other items. The index was designed as an aid towards protecting ordinary workers from price rises associated with the First World War. It continued throughout the 1920 s and 1930s but was increasingly criticised particularly in relation to the weights used. These were based on data from a 1904 survey of urban working class households' expenditure and were influenced by subjective judgements of what constituted legitimate expenditure for a working class family. For example, beer was completely excluded. In 1936, the then Ministry of Labour announced its intention to update the weights using the results from a large-scale household expenditure survey carried out in 1937-38. However, by the time the results became available, war had broken out and further action was deferred.

\section{Retail Prices Index}

In 1946, a Cost of Living Advisory Committee was set up. This Committee produced an interim report in 1947 which advised that as a short-term measure, the weights of the cost of living index should be updated using the results of the 1937-38 household expenditure survey but that a new inquiry to collect spending data should be introduced. It also recommended fundamental changes in the selection and number of representative items for which prices should be collected. The resulting index, the Interim Index of Retail Prices, began in June 1947 and continued with some minor modifications to 1956. By 1955, sufficient information from the Household Budget Inquiry became available to underpin a new index and this became the first official Retail Prices Index beginning in January 1956. The changes introduced at this stage included:

- the expansion of households included from working class to all wage earners but excluding very high and low-earning households.

- a firm definition of the RPI.

- a definition of the scope of the index in terms of which goods and services should be included.

- a new structure for spending categories. 
The Cost of Living Advisory Committee also recommended that the Household Budget Survey should become a continuous survey and this led to the creation of the Family Expenditure Survey in 1957. The results from this survey meant that the weights used in the RPI could be updated annually and this process began in 1962.

Various relatively minor changes were introduced in the 1960 s and 1970 s including:

- the introduction of a meals out group from 1968.

- the construction of separate pensioner indices from 1969.

- several changes to the methods of calculating owner-occupiers' housing costs including the introduction of a new method of calculating mortgage interest payments from 1975.

- the introduction of the all items RPI excluding mortgage interest payments which later became known as RPIX and, in 1992, became the basis for the inflation target.

- the introduction of seasonal weights for fresh fruit and vegetable items from 1975.

- the introduction of a new index, the Tax and Price Index from 1979.

A new RPI Advisory Committee was convened in the early 1980s and this produced a wideranging report in 1986 which led to many changes to the definition, scope and coverage, the treatment of subsidies and discounts, and the treatment of owner-occupiers' housing costs. Two further Advisory Committees met during the 1990s and their recommendations led to further improvements to the index. The main RPI Advisory Committee recommendations are described in appendix 2 to the Consumer Price Indices Technical Manual ${ }^{4}$. Between 1995 and 2008, improvements were made via a series of protocols between the ONS, Bank of England and HM Treasury. More information on the institutional relationships at this time were described in a December 2001 article "ONS and the Inflation Target" by Amanda Rowlatt 5 .

Since 1990, changes made to the RPI include the introduction of:

- a component for foreign holidays from 1993.

- UK holidays from 1994.

- a new element of housing costs, depreciation, from January 1995.

- random sampling of locations for price collection in 1995.

- a new index in 1995, commonly known as RPIY, designed to measure movements in underlying prices by excluding price changes that are directly due to changes in indirect taxation as well as movements in mortgage interest rates.

- local probability sampling for the selection of some high turnover, high technology goods within retail outlets in 2004 . 
- hedonic regression for the quality adjustment of personal computers and digital cameras in 2004.

The Statistics and Registration Services Act $2007^{6}$ established new arrangements for the governance of the RPI. Since then, proposed changes require the approval of the Statistics Authority. Two changes to methodology have been introduced during this time:

- the use of an average effective rate instead of the standard variable rate in the measurement of mortgage interest payments ${ }^{7}$.

- the way in which prices of seasonal items are measured within the RPI (and CPI).

Much of the history and development of the RPI are described in appendix 1 to the Consumer Price Indices Technical Manual ${ }^{4}$ and in a series of articles published on the national statistics website $^{9}$

\section{Consumer Prices Index}

The CPI has a much shorter history than the RPI. It was first introduced in 1996 as the Harmonised Index of Consumer Prices (HICP). HICPs were developed across the European Union for the purpose of assessing whether prospective members of European Monetary Union would pass the inflation convergence criteria and of acting as a measure of inflation used by the European Central Bank to assess price stability in the Euro area. A major requirement, then, was for a consistent measure of inflation across Europe in order to make reliable comparisons between EU Member States. Such comparisons are not generally possible using the RPI and the historical national price indices in other Member States due to differences in index coverage and construction.

The HICP is specified in a series of legally binding European regulations. Regulation number 2494/95 of 23 October 1995 provides the legal basis of the HICP and a series of subsequent regulations signed between 1996 and 2007 define its construction and coverage. The HICP regulations are drafted by the European Commission in conjunction with experts from Member States and the European Central Bank through an HICP Working Party. The work is overseen and approved by the Statistical Programme Committee made up of heads of EU National Statistical Institutes (ONS in the UK) and the head of the European Statistical Office (Eurostat). Like other Member States, the UK can influence the legislation but can not dictate it. Regulations normally require a qualified majority vote before they are brought forward for legislation.

Once introduced, the regulations are obligatory in every Member State. Eurostat undertakes an ongoing monitoring programme to evaluate compliance with the regulations.

In December 2003, the National Statistician decided that the name of the UK version of the HICP would change to the Consumer Prices Index (CPI) in all National Statistics publications though there was no intention to develop the CPI differently from the HICP. This decision was concurrent with the Chancellor of the Exchequer's Pre-Budget Report 2003 announcement that the UK inflation target would in future be based on the HICP, replacing the RPI excluding mortgage interest payments. The reasons for the change were set out by the Treasury in the Pre-Budget Report 2003 and in the Appendix attached to the new remit for the Bank of England's Monetary 
Policy Committee. At the time, the Chancellor confirmed that pensions, benefits, and index-linked gilts would continue to be calculated on the same basis as previously, that is with reference to the all items RPI or its derivatives. However, in the June 2010 budget, the Chancellor announced changes to the method for uprating benefits. The 2010 Budget Report said:

"The Government will adopt the CPI for the indexation of benefits, tax credits and public service pensions from April."

"The Government will uprate the basic State Pension by a triple guarantee of earnings, prices or 2.5 per cent, whichever is highest, from April 2011. CPI will be used as the measure of prices in the triple guarantee, as for other benefits and tax credits. However to ensure the value of a basic State Pension is at least as generous as under the previous uprating rules, the Government will increase the basic State Pension in April 2011 by at least the equivalent of RPI."

Since its introduction, there has been a series of changes to the CPI:

- the expenditure used for weighting purposes in 2000 was extended to include spending in the UK by foreign visitors and residents of institutional households.

- coverage was extended to cover health in 2000.

- education charges were introduced in 2001.

- financial services expressed as a proportion of the transaction value were introduced in 2002, for example, stockbroking and unit trust charges, foreign currency exchange.

- hedonic regression was introduced in 2003 for the quality adjustment of personal computers and subsequently for other items starting with digital cameras in 2004.

- local probability sampling for the selection of some high turnover, high technology goods within retail outlets began in 2004 .

- analysis of the CPI according to detailed goods and services came in 2005.

- CPI excluding indirect taxes (CPIY) was introduced in 2006, designed to measure movements in underlying prices by excluding price changes that are directly due to changes in indirect taxation.

- $\mathrm{CPI}$ at constant tax rates (CPI-CT) was introduced in 2006, with the difference between $\mathrm{CPI}$ and $\mathrm{CPI}-\mathrm{CT}$ designed to show the contribution of tax changes to the overall CPI inflation figures.

Again the developments are described in a series of articles published on the national statistics website $^{9}$. 


\section{Similarities Between CPI and RPI}

Differences between the CPI and RPI have been described in a number of articles and will be covered later. It is worth, however, emphasising the similarities between the two.

Firstly both indices are based on a fixed basket of goods and services within each year. In principle, this basket should contain all consumer goods and services purchased by households and the prices measured in every shop or outlet that supplies them. In practice, this is impossible and unnecessary since a good measure can be calculated based on a sample of representative goods and services from a representative selection of retail outlets.

Both the CPI and RPI are currently produced by combining together around 180,000 price quotes collected each month against a list of over 650 representative goods and services. Around 110,000 quotes are collected from around 20,000 retail outlets in over 140 locations around the country. The remainder are collected centrally, mostly from the internet, for example, for efficiency reasons where a multiple retailer has a national pricing policy, or for non-store spending such as theatre and sporting event admission charges, utility prices and general purchases over the internet.

The implication of a fixed basket within year is that as prices change over time, the relative quantities of each product purchased remain constant. Thus within year movements reflect only changes in prices.

Secondly, neither the CPI nor the RPI is a cost of living index. This concept is difficult to define in practice. Some use it to mean a measure of the cost of buying sufficient quantities of various items to maintain some minimal standard of living. Defining this standard is subjective however and if it rises over time, this would influence such an index. Another definition is of an index calculated in the same way as the CPI or RPI but restricted to basic essentials. However the definition of a basic essential is also subjective and tends to change over time with former luxuries such as telephones now usually considered essential.

In economic terms, a cost of living index can be defined as the minimum expenditure at this month's prices required to achieve the same level of utility as in some earlier period, relative to the expenditure in that earlier period. There is no assumption that the relative quantities of goods and services purchased in the two periods is the same so the concept is quite different to fixed basket indices such as the CPI and RPI. Due to the use of the word "minimum" in the definition, a cost of living index usually gives a lower rate of inflation than the CPI or RPI. In other words, when prices rise, provided consumers have a choice, they can always achieve a given standard of living at lower cost by varying the relative quantities of the goods and services they purchase compared with the increase in overall spending on a fixed bundle of goods and services. Consumers basically substitute purchases of relatively expensive items for similar goods that have become relatively cheaper. This helps to limit the rise in the cost of the shopping basket when there is a general increase in the cost of goods and services overall.

An alternative way of viewing this is that a fixed basket of goods and services overstates the extent to which consumers' expenditure must rise to maintain constant utility as prices rise. The degree to which fixed basket price indices may overstate changes in the cost of living depends on the scale of price changes. A fuller discussion of this issue including algebraic and numerical examples is 
included in an article entitled "The new inflation target: the statistical perspective" by David Roe and David Fenwick ${ }^{10}$.

In practice, the potential problem of a fixed basket overstating changes in the cost of living is minimised by regularly updating the contents of the $\mathrm{CPI}$ and RPI baskets and the expenditure weights associated with them. This is a third similarity between the two sets of indices. Both the $\mathrm{CPI}$ and RPI baskets and weights are updated annually, and the resulting within year indices chained together to form a single price index spanning many years. This annual updating helps to ensure that the indices remain representative of consumer spending patterns over time.

Other similarities between the two families of indices include:

- the vast majority of goods and services priced are common to the two.

- the same price quotes collected for these items from the same retail outlets and locations are used in constructing the two sets of indices.

- the prices generally reflect a point in the middle of the month (although the collection of prices over a longer period is being investigated to meet a European Regulation on temporal sampling).

- the validation techniques used to ensure the quality of the data are consistent.

- decisions on whether products replacing discontinued or unavailable lines are comparable with the replaced product and, as a result, can be included in index calculation are consistent.

- the use of hedonic regression to adjust for quality changes in certain new technology goods (namely personal computers, laptop computers, digital cameras and mobile phone handsets) is the same.

- the same computer systems and procedures are used to compile the two.

- both indices are published at the same time and in the same formats on the National Statistics website.

\section{Differences Between CPI and RPI and the Resulting Implications}

The main differences between the two sets have been described previously in a variety of forms, and most recently summarised in an Information Note "Differences between the RPI and CPI measures of inflation"11. The differences and the implications of those differences are described below.

\section{Population Base}

This is the population whose spending patterns are used in calculating the weights used to combine prices for different items. In effect it is the population of consumers whose spending is being covered by the indices. 
The CPI is based on spending by all private and institutional households, for example university halls of residence and nursing homes. The RPI however excludes the highest earning households, namely the top four per cent of households by income, and pensioner households with three quarters of their income coming from state pensions and benefits. These exclusions represent around 13 per cent of private household spending. The RPI also excludes institutional households.

The CPI also includes spending by foreign visitors to the UK but spending by UK households abroad is excluded. Conversely the RPI excludes spending by foreign visitors but includes spending by UK households when abroad.

The logic behind the exclusion of pensioners and high earners from the RPI is that such households are likely to spend their money on atypical items and including them in the scope of the RPI would distort the overall average. The exclusion of such households is not common in other countries and the position taken in European legislation, which the CPI follows, is different.

The source of the spending data for the RPI is a household survey conducted by the ONS known as the Living Costs and Food Survey. This is a descendent of the Family Expenditure Survey used to update the weights annually from 1962. The source of spending data for the CPI is Household Final Monetary Consumption Expenditure taken from the National Accounts. The use of this information is compliant with European legislation and ensures greater coherence with other economic data giving it an advantage over the RPI as a macroeconomic indicator of inflation. More generally, the differences in the population base are one of the factors that need to be considered by users when deciding on the appropriateness for a specific purpose. Is it more appropriate to consider domestic spending in total regardless of consumer or is it more appropriate to restrict spending to a subset of domestic households but regardless of whether the spending is in the UK or overseas?

\section{Commodity Coverage}

The CPI again follows National Accounts concepts of what constitutes household consumption when determining the range of commodities to be priced, while the RPI has used evidence of spending from the Living Costs and Food Survey and its predecessors to determine coverage largely in a pragmatic way. The result is that while the vast majority of goods and services that are priced are included in both the CPI and RPI, there are a small number of important differences.

The most well-known of the differences is in the area of housing and, in particular owner occupied housing costs. At present, these are largely excluded from the CPI but included in the RPI. The $\mathrm{CPI}$ excludes housing since there have been difficulties in establishing an international consensus on how it should be measured, reflecting the diverse treatment of such costs in national price indices and perhaps behind that, the different types of housing and housing finance across countries. In detail, the CPI excludes the following housing related items which are included in the RPI:

- $\quad$ mortgage interest payments.

- house depreciation. 
- buildings insurance and ground rent.

- house transaction costs such as estate agents' fees, home buyers' survey costs and conveyancing charges.

- council tax - this is treated as a direct tax in the National Accounts so is not considered to be household consumption, and hence is excluded from CPI coverage based on Household Final Monetary Consumption in the National Accounts.

The development of price indices in the area of housing costs is work that the ONS is actively involved in and, indeed, is one of the leaders in Europe in this area. More information on this work was published in the 2010 Annual Report of the Consumer Prices Advisory Committee to the UK Statistics Authority ${ }^{12}$ and in other Advisory Committee papers ${ }^{13}$.

The CPI also excludes television and road fund licences whereas they are included in the RPI. Their inclusion in the RPI is historical, perhaps reflecting the origins of the RPI as a cost of living index. They have been excluded from the CPI since they, like council tax, are considered to be taxes and do not constitute household final monetary consumption expenditure under national accounting rules. Trades union subscriptions are also excluded from the CPI as not part of consumption expenditure.

Conversely the CPI includes but the RPI excludes university accommodation fees, foreign students' university tuition fees, and some financial services such as unit trust and stockbrokers charges. This treatment reflects the population base of the two indices with the CPI population additionally including institutional households, foreign visitors to the UK and high income households.

There are two other detailed differences in the way in which commodities are measured or included in the CPI and RPI:

- in the RPI, new car prices are imputed on the basis of movements in second-hand car prices. Conversely, the $\mathrm{CPI}$ includes a specific index for new cars based on the list prices of a range of models and manufacturers, and adjusted for quality change as new models are introduced using the technique of option costing. This technique is explained in more detail in the Consumer Price Indices Technical Manual ${ }^{4}$. As mentioned in the Consumer Prices Advisory Committee 2010 Annual Report ${ }^{12}$, the measurement of car prices in both the CPI and RPI is currently being investigated, partly with a view to developing a consistent approach for $\mathrm{CPI}$ and $\mathrm{RPI}$, and partly to improve on the use of list prices by measuring actual transaction prices.

- in the RPI, all expenditure on insurance is considered to belong to the relevant insurance heading (for example, housing or motor insurance premiums). By contrast, in the $\mathrm{CPI}$, the amount paid out in claims is distributed among other spending categories according to the nature of the claim with only the residual (that is, the service charge) allocated to the relevant insurance heading. 
Again, users have to decide on the more appropriate commodity coverage of CPI and RPI when considering which is more appropriate for their purposes. In particular, should owner occupied housing costs be included and are the other lesser differences important for their use?

\section{Index Construction Formula}

Both the $\mathrm{CPI}$ and RPI are constructed from the bottom up by weighting together the individual price quotes into a succession of higher level sub-indices up to the all items indices. The first stage of the calculation is to combine the 180,000 price quotes into around 5,000 "elementary aggregates". These elementary aggregates are usually below the level of the 650 items in the basket and they are generally defined either by shop-type (multiple or independent) or the region of the country where the prices were collected. At this level of detail, there is no expenditure information from which to calculate relative weights so a simple average of prices is used to compute each of the elementary aggregates.

At this first stage of aggregation, the CPI uses a mix of geometric mean and arithmetic mean to produce elementary aggregates whereas the RPI uses arithmetic means. The arithmetic means are historical and came through under the auspices of the historical Cost of Living and RPI Advisory Committees. The aggregation formulae that are allowed for use in the CPI were specified in European Regulation.

There are two types of arithmetic mean used in the RPI:

- the first is a ratio of averages (often referred to as a Dutot index). This compares the average of prices in the current period with the average of matching prices in the base period to create an index for the elementary aggregate.

- the second is an average of price relatives (often referred as a Carli index). For each pair of matching prices, this calculates the ratio of price in the current period with the price in the base period and it then takes an average of these ratios.

The ratio of averages gives greatest weight to the highest priced products or brands in estimating price change overall. For this reason it is mainly used for fairly tightly defined products such as food, alcohol and tobacco so that the estimate of price change should not be unduly dominated by any particular product. The average of relatives gives equal weight to all price relatives and is used for products such as clothing and furniture where wider variations in prices limits the application of the ratio of averages.

The CPI mostly uses the geometric mean for the first stage of aggregation. This is calculated as the geometric mean of prices in the current period relative to the geometric mean of the matching prices in the base period, though an identical result would be obtained from taking the geometric mean of the price relatives. In practice, the geometric mean is used to produce the elementary aggregates for around 70 per cent of the CPI basket by expenditure weight. Elsewhere the ratio of averages is used. The European regulation permits the use of both geometric mean and the ratio of averages but does not endorse the average of relatives. 
A detailed discussion of the properties of the different formulae and the economic conditions in which they are most suitable is included in "The new inflation target: the statistical perspective" by David Roe and David Fenwick ${ }^{10}$. In summary:

- the average of relatives always produces a higher result than the geometric mean for a given set of relatives (except when the values are all equal).

- the ratio of averages can produce a higher or lower result than the geometric mean depending on the coefficients of variation of prices in the current and base periods.

- the use of arithmetic means, particularly the average of relatives, in the RPI as opposed to the combination of geometric mean and ratio of averages in the CPI results in the former showing a higher rate of change for given price data.

- the geometric mean formula implicitly assumes that consumers will switch to cheaper alternatives when relative prices change whereas the arithmetic mean is consistent with no substitution between products.

- in certain circumstances, when combined with chain linking as used in both CPI and RPI, the use of the average of relatives for aggregation can introduce an upward bias in the overall price index.

To the extent that it is considered desirable to allow for substitution between products, the geometric mean has advantages over the arithmetic mean, and particularly over the average of relatives which can exhibit upward bias. In the $\mathrm{CPI}$, items where substitution is less likely such as energy and fuel have elementary aggregates calculated using the arithmetic mean. However where substitution is more likely such as food and clothing, a geometric mean is used. The earlier discussion about cost of living indices mentioned that the potential issue of a fixed basket overstating changes in the cost of living can be minimised by regularly updating the contents of the $\mathrm{CPI}$ and RPI baskets and the expenditure weights associated with them. The use of the geometric mean to produce elementary aggregates for items where substitution is more likely brings the fixed basket approach of the CPI yet closer to a cost of living index.

\section{Product Coding}

Although the vast majority of items covered are in both CPI and RPI, the classification systems used for aggregation and publication of results differ. Alongside the population base and commodity coverage, the classification system used in the CPI is based on National Accounts principles and aids coherence with other economic data. It uses an international system for classifying household consumption expenditure known as Classification of Individual Consumption by Purpose or COICOP. The RPI is based on a long-standing system specified and developed by earlier Cost of Living and RPI Advisory Committees. The different approaches reflect the fact that the $\mathrm{CPI}$ is used to compare inflation rates across Europe so a standard framework is required whereas the RPI is mainly used within the UK only. 


\section{Rounding}

Finally, in terms of the main differences between the two indicators, the rounding procedures are different. Although both sets of indices are calculated using full precision, the monthly and twelve month rates from the $\mathrm{CPI}$ are calculated using unrounded indices whereas those from the RPI are calculated from rounded indices. To some extent, the difference arises from the historic use of the two series: the CPI was and is used for macroeconomic purposes as an inflation target so full precision has been used in deriving the rates. The RPI has historically been used for indexing purposes, for example, in wage bargaining, and by calculating rates from published index numbers, it prevents any possible confusion or dispute arising from published rates not tying up with rates calculated from published index numbers. Rounding is one of the projects listed in the future work programme in the Consumer Prices Advisory Committee Annual Report ${ }^{12}$.

\section{Governance and Procedures for Change}

Governance of the indices has evolved throughout their history as described earlier but is different for $\mathrm{CPI}$ and $\mathrm{RPI}$. The $\mathrm{CPI}$ is governed by a series of European Regulations which are legally binding. The UK, then, can not make changes to the CPI unilaterally unless it were to introduce a national version distinct from the version currently produced to meet international requirements.

Governance of the RPI is enshrined in the Statistics and Registration Services Act $2007^{6}$. Section 21 of the Act requires the Statistics Authority to compile and maintain the RPI and publish it every month. It further requires that before making any change to the coverage or basic calculation of the index, the Authority must consult the Bank of England as to whether the change constitutes a fundamental change in the index which would be materially detrimental to the interests of the holders of relevant index-linked gilt edged securities. If the Bank of England considers that that change is a fundamental change in the index which would be materially detrimental to the holders of index-linked gilts, the Authority may not make the change without the consent of the Chancellor of the Exchequer.

Any methodological changes to the RPI therefore require the approval of the Authority before being referred to the Bank of England. To facilitate this, the Authority established a body to advise it on proposals for change to the RPI. This body is called the Consumer Prices Advisory Committee and it has three distinct roles:

- to advise the UK Statistics Authority on the implication for the RPI of the improvements to this index recommended by the ONS.

- to provide the UK Statistics Authority with advice on RPI Methodological issues.

- to advise the UK Statistics Authority on improvements to the UK CPI recommended by ONS.

The new governance framework enables:

- improvements to the RPI to be introduced though it is still not easy to make changes.

- development of greater alignment of RPI and CPI methods. 
- ONS to have access to external expertise on inflation.

- greater transparency of proposals for change with CPAC papers published on the National Statistics website.

- clear and efficient decision making processes.

\section{Strengths and Weaknesses of the CPI and RPI}

Some of the strengths and weaknesses of the CPI and RPI have been described in the preceding sections. A further comparison in relation to the uses made of the indices will be included in a future article to be published on the National Statistics website on 16 August 2011. This will consider in particular their use as a macroeconomic indicator of inflation and as a compensation index.

\section{Future Work Programme}

Within consumer prices, the CPI is increasingly becoming the main measure of price change used for a wide variety of purposes. As a result, higher priority is attached to the need to continuously improve the CPI compared with the RPI. Proposals for change are aimed at improving the CPI while maintaining the RPI. The main example of CPI development priority is work on owner occupiers' housing costs. However, ONS is taking forward a wide-ranging development agenda for consumer price statistics which will impact on both CPI and RPI. The projects include:

- measurement of rents in the CPI and RPI.

- measurement of car prices in the CPI and RPI.

- reviewing the selection of the sample of locations used in collecting data for the CPI and RPI.

- reviewing the optimum base period used in the construction of the CPI and RPI.

- speeding up publication of CPI and RPI.

- reviewing the data collection methods for $\mathrm{CPI}$ and $\mathrm{RPI}$.

- reviewing temporal coverage of $\mathrm{CPI}$ and $\mathrm{RPI}$.

Much more detail on the work programme in general and on the individual projects listed above was included in the CPAC 2010 Annual Report ${ }^{12}$. Updates on the work are published in the form of CPAC papers available on the National Statistics website ${ }^{13}$. As always the ONS welcomes comments and views on the programme and the priorities afforded each of the projects. Comments should be sent to cpi@ons.gov.uk. 


\section{Further Information}

For further information please contact Philip Gooding 01633455896.

Alternatively email cpi@ons.gov.uk.

\section{References}

${ }^{1}$ Code of Practice for Official Statistics - http://www.statisticsauthority.gov.uk/assessment/code-of-practice/index.html

${ }^{2}$ UK Statistics Authority Assessment Report 79: Consumer Price Indices http://www.statisticsauthority.gov.uk/assessment/assessment/assessment-reports/index.html

${ }^{3}$ Consumer Price Inflation since 1750 - http://www.statistics.gov.uk/cci/article.asp?id=726

${ }^{4}$ Consumer Price Indices Technical Manual - http://www.statistics.gov.uk/statbase/product.asp?vlnk=2328

${ }^{5}$ ONS and the Inflation Target - http://www.statistics.gov.uk/cci/article.asp?ID=102

${ }^{6}$ The Statistics and Registration Services Act 2007 http://www.opsi.gov.uk/Acts/acts2007/pdf/ukpga_20070018_en.pdf

${ }^{7}$ Consultation on the Measurement of Mortgage Interest Payments within the Retail Prices Index http://www.ons.gov.uk/about/consultations/closed-consultations/measurement-of-mortgage-interest-payments-withinthe-retail-prices-index--2009-/index.html

${ }^{8}$ Consultation on the Measurement of Seasonal Items within the Consumer Prices Index and Retail Prices Index http://www.ons.gov.uk/about/consultations/closed-consultations/measurement-of-seasonal-items-within-the-cpi-andrpi/measurement-of-seasonal-items-within-the-cpi-and-rpi.html

${ }^{9}$ List of historical articles on CPI and RPI - http://www.statistics.gov.uk/about/methodology by theme/CPI/

${ }^{10}$ The new inflation target: the statistical perspective - http://www.statistics.gov.uk/cci/article.asp?id=688

${ }^{11}$ Differences between the RPI and CPI measures of inflation -

http://www.statistics.gov.uk/downloads/theme economy/cpi-rpi-information-note.pdf

${ }^{12}$ Consumer Prices Advisory Committee 2010 Annual Report to UK Statistics Authority http://www.statistics.gov.uk/downloads/theme economy/cpac-annual-report2010.pdf

${ }^{13}$ Consumer Prices Advisory Committee papers - http://www.ons.gov.uk/about-statistics/developmentprogrammes/other-development-work/prices-advisory-committee/index.html 